\title{
Diurnal cortisol amplitude and fronto-limbic activity in response to stressful stimuli
}

\section{Citation}

Cunningham-Bussel, Amy C., James C. Root, Tracy Butler, Oliver Tuescher, Hong Pan, Jane Epstein, Daniel S. Weisholtz, et al. 2009. "Diurnal Cortisol Amplitude and Fronto-Limbic Activity in Response to Stressful Stimuli." Psychoneuroendocrinology 34 (5) (June): 694-704. doi:10.1016/j.psyneuen.2008.11.011.

\section{Published Version}

10.1016/j.psyneuen.2008.11.011

\section{Permanent link}

http://nrs.harvard.edu/urn-3:HUL.InstRepos:37166086

\section{Terms of Use}

This article was downloaded from Harvard University's DASH repository, and is made available under the terms and conditions applicable to Other Posted Material, as set forth at http:// nrs.harvard.edu/urn-3:HUL.InstRepos:dash.current.terms-of-use\#LAA

\section{Share Your Story}

The Harvard community has made this article openly available.

Please share how this access benefits you. Submit a story.

\section{Accessibility}




\section{Summary}

The development and exacerbation of many psychiatric and neurologic conditions are associated with dysregulation of the hypothalamic pituitary adrenal (HPA) axis as measured by aberrant levels of cortisol secretion. Here we report on the relationship between the amplitude of diurnal cortisol secretion, measured across 3 typical days in 18 healthy individuals, and blood oxygen level dependant (BOLD) response in limbic fear/stress circuits, elicited by in-scanner presentation of emotionally negative stimuli, specifically, images of the World Trade Center (WTC) attack. Results indicate that subjects who secrete a greater amplitude of cortisol diurnally demonstrate less brain activation in limbic regions, including the amygdala and hippocampus/ parahippocampus, and hypothalamus during exposure to traumatic WTC-related images. Such initial findings can begin to link our understanding, in humans, of the relationship between the diurnal amplitude of a hormone integral to the stress response, and those neuroanatomical regions that are implicated as both modulating and being modulated by that response.

\footnotetext{
(C) 2008 Elsevier Ltd. All rights reserved.

*Corresponding author: Tel.: +1 212746 8025; fax: +1 212746 5818. amc2015@med.cornell.edu (A.C. Cunningham-Bussel).

${ }^{1}$ Both authors contributed equally to this work.

Conflicts of interest statement

None declared.
} 


\section{Keywords}

Amygdala; Medial prefrontal cortex; Hippocampus; Cortisol; Neuroimaging; Stress

\section{Introduction}

Animal research and recent human neuroimaging studies (Wang et al., 2005; Urry et al., 2006; Liberzon et al., 2007) have drawn attention to the role of the amygdala, ventral medial prefrontal cortex (vmPFC) and hippocampus as regions critically involved in both emotional/fear processing and regulation of the hypothalamic pituitary adrenal (HPA) axis (Herman et al., 2005; Urry et al., 2006). Activation of the HPA axis in response to stressors (physiological or psychological disturbances perceived to threaten an organism's homeostasis) leads to a cascade of molecular events resulting in the production of glucocorticoids: cortisol in humans and corticosterone in rodents (Herman and Seroogy, 2006; Bremner, 2006). The HPA axis maintains a strong diurnal glucocorticoid rhythm, which peaks in the first $30 \mathrm{~min}$ after awakening and falls throughout the remainder of the day to negligible amounts during the evening nadir (Clow et al., 2004; Herman and Seroogy, 2006). The amount of cortisol released at the peak of the diurnal cycle can be similar to the amount released during a stress response (Herman and Seroogy, 2006).

Cortisol is involved in modulating many beneficial processes relevant to stress-related situations (Charney, 2004). However, prolonged or repeated stress has been associated with cognitive impairment and structural brain changes (McEwen, 2002; Lupien et al., 2002; Charney, 2004; McEwen, 2005; Radley and Morrison, 2005; Oei et al., 2006).

Both stress and fear processes are interrelated as they are modulated both by overlapping neuroanatomical regions, such as the amygdala, hippocampus and prefrontal cortex and secreted products including cortisol. Indeed, prolonged exposure to stress hormones and limbic activity elicited under conditions of chronic stress may result in increased arousal to novel stimuli, and the generation of memories of fear (Miller and McEwen, 2006). Extensive animal literature has indicated that the influence of particular limbic centers on HPA axis functioning is "region and stressor specific" (Herman et al., 2005). In humans, physical stressors such as electric shock and psychological stressors (e.g. mental arithmetic) can activate the HPA axis, eliciting a cortisol response; however reliable associations between specific psychological stressors and HPA axis activation remains unclear, particularly in regards to emotion inducing stimuli (Kemeny and Dickerson, 2004).

Psychiatric illnesses including post-traumatic stress disorder (PTSD) and depression are frequently associated with dysregulated diurnal cortisol rhythm (McEwen, 2002; SotresBayon et al., 2004; Clow et al., 2004; Neylan et al., 2005; Risbrough and Stein, 2006; Herman and Seroogy, 2006; Rauch et al., 2006; Mackenzie et al., 2007). With exceptions, many PTSD patients exhibit both hypocortisolemia and increased suppression of cortisol following dexamethasone administration as compared to healthy controls (Yehuda et al., 1991; Young and Breslau, 2004; Olff et al., 2006; Bierer et al., 2006). In contrast, depressed patients often demonstrate both chronic diurnal hypercortisolemia and less dexamethasone 
suppression of cortisol relative to healthy subjects (Kathol et al., 1989; Holsboer, 2000; Yehuda, 2002; McEwen, 2005).

In addition to and not unrelated to their regulation of the HPA axis, the amygdala, mPFC and hippocampus are known to play key roles in the processing of emotional (including fear) stimuli in the present study and in others (Lane et al., 1997; Gur et al., 2002; Taylor et al., 2003; Phan et al., 2004; Britton et al., 2006; Dannlowski et al., 2007). Furthermore, patients with psychiatric disorders, and anxiety disorders specifically, demonstrate aberrant frontolimbic neural activity as documented by a large number of neuroimaging studies (Rauch et al., 2006). To date, however, only a few studies have begun linking these endocrine and neuroimaging findings in patient (Bonne et al., 2003; Liberzon et al., 2007) and healthy (Wang et al., 2005; Urry et al., 2006) populations. Urry et al. (2006) demonstrated in older adults an inverse relationship between the diurnal cortisol rhythm (sampled for 1 week prior to scanning) and BOLD activation in regions such as the amygdala in response to emotionally negative pictures. The present study therefore, though distinct, builds upon the previous work by Urry et al. (2006) to assess the relationship between the amplitude of daily cortisol release and activation in limbic brain regions (amygdala, mPFC, hippocampus/parahippocampus and hypothalamus) in response to emotionally negative, stress-related images of the WTC attacks in healthy participants. In accordance with prior findings in humans (Urry et al., 2006) and animals (Diamond et al., 1992; Herman et al., 2005; Herman and Mueller, 2006) we hypothesized that the hippocampus and vmPFC will demonstrate a negative correlation with an index of diurnal salivary cortisol and that the amygdala will demonstrate a positive correlation.

\section{Materials and methods}

\subsection{Subjects}

18 healthy right-handed subjects, 11 male and 7 female, average age of 31 (S.D. 8.8) participated in fMRI scanning as part of this research study. All subjects were present in New York City at the time of the World Trade Center attacks, but were not directly exposed to the disaster (all subjects were greater than 2 miles from the WTC site on 9/11/2001.) No subject had a current or prior diagnosis of PTSD or any other psychiatric disorder, as assessed by Structured Clinical Interview for DSM-IV (SCID). Additionally, no subject was taking any medication. Subjects were recruited through advertisements placed in newspapers and flyers distributed throughout New York. All subjects gave informed consent prior to scanning. This study was approved by the New York Presbyterian Hospital-Weill/Cornell Institutional Review Board. Subjects were scanned an average of 939 days (S.D. 209) after the $9 / 11$ attacks.

\subsection{Study design and stimuli}

Subjects participated in a single scanning session consisting of five runs. Each run included six blocks. During each block, eight full-color images corresponding to one (of six) experimental condition were individually presented. Each image was presented only once. Image stimulus conditions were as follows: the World Trade Center (WTC) attack; New York City (NYC) unrelated to the attack; the Vietnam War (VIE); suburbs (SUB); 
countryside (COU); and scrambled images (SCR) (Fig. 1). Scrambled images were created from meaningful images using a MATLAB algorithm that rearranged groups of pixels, preventing recognition while preserving basic visual properties. Images related to the September 11th World Trade Center attack were used as stress-related, threatening stimuli. Comparison stimuli were used to control for non-emotional content and low-level visual characteristics. For each condition, there were 40 different images presented in six blocks over the course of the experiment. Presentation order of blocks was pseudorandomized to control for time/order effects. Each image was presented for $2000 \mathrm{~ms}$ with an average interstimulus interval of $2800 \mathrm{~ms}$ during which a fixation cross was presented. There was a resting inter-block interval of $28.8 \mathrm{~s}$. After each image appeared on the screen, subjects were asked to press a button located under their right index finger to indicate that the subject had seen the image. The task engagement of this response was used to indicate in scanner subject participation and to assess condition effects. Separate paired $t$-tests were calculated to assess differences in reaction times across conditions. Presentation of the stimuli was controlled by the Integrated Functional imaging System (IFIS; MRI Devices Inc., Gainesville, FL) in coordination with Eprime software (Psychology Software Tools Inc., Pittsburg, PA).

Following the scan, 17 of 18 subjects rated the valence of the stimuli presented to them during MRI scanning, using a seven-point scale, ranging from negative three (most negative) to positive three (most positive) with negative and positive valences represented, respectively, by negative and positive numbers.

\subsection{Cortisol collection and analysis}

Cortisol samples were collected using cotton swabs (Sarstedt, Newton, NC). Subjects were instructed to place the cotton swab in their mouths for approximately 2 min until saliva had accumulated in the cotton. The swab was then placed inside of a plastic tube for storage. Four cortisol samples were collected on each of 3 days. Subjects were asked to collect saliva immediately upon waking (WU), $30 \mathrm{~min}$ following their wake up (WU+30), and at $1700 \mathrm{~h}$ and $2000 \mathrm{~h}$ later that day. Subjects recorded the actual time that they took the sample. According to (Hellhammer et al., 2007) measuring the cortisol values on 3 separate days provides a reliable trait measure of cortisol. Saliva samples were then stored at $-70{ }^{\circ} \mathrm{C}$ prior to analysis. Analysis of salivary cortisol was performed by a research laboratory at Weill/ Cornell Medical Center using a salivary cortisol enzyme immunoassay kit. Optical density was read on a standard plate reader at 450 (Salimetrics LLC, State College, PA). Each sample was divided into two wells and assayed twice in order to ensure reliability of the sample. A diurnal cortisol index was generated with the following equation:

$$
\frac{\text { Average(WU or WU+30 Max }) \text {-Average }(1700 \mathrm{~h} \text { or } 2000 \mathrm{~h} \text { Min })}{\text { Average(WU or WU+30 Max })+ \text { Average(1700 h or } 2000 \mathrm{~h} \text { Min) }}
$$

Average (WU or WU +30 ) represents the average of the maximum cortisol value among the WU and WU +30 samples for each of the 3 days and Average ( $1700 \mathrm{~h}$ or $2000 \mathrm{~h} \mathrm{Min)}$ signifies the average of the minimum value among the last two cortisol samples taken for each of the 3 days. This index reflects the daily excursion of cortisol level over a normal 
day, and is sensitive to both a high wake up value and/or a low evening value. This diurnal cortisol index was entered as the covariate of interest in image analysis.

\subsection{Image acquisition}

Image data were acquired with a GE Signa 3 T MRI-scanner (max gradient strength 40 $\mathrm{mT} / \mathrm{m}$, max gradient slew rate $150 \mathrm{~T} /(\mathrm{m} / \mathrm{s})$ ) (General Electric Company, Waukesha, Wis.). T1 weighted whole-brain anatomical images were acquired using a spoiled gradient recalled acquisition sequence (resolution $0.9375 \mathrm{~mm} \times 0.9375 \mathrm{~mm} \times 1.5 \mathrm{~mm}$ ). After shimming to maximize homogeneity, a series of $3 \mathrm{~T}$ fMRI scans were collected using a gradient echo echo-planar imaging (EPI) sequence $\left(\mathrm{TR}=1200 ; \mathrm{TE}=30\right.$; flip angle $=70^{\circ} ; \mathrm{FoV}=240 \mathrm{~mm}$; 15 slices; $5 \mathrm{~mm}$ thickness with $1 \mathrm{~mm}$ inter-slice space; matrix $=64 \times 64)$, with a modified $\mathrm{z}$ shimming algorithm to reduce susceptibility artifact at the base of the brain (Gu et al., 2002). For co-registration purpose, a reference $\mathrm{T} 1$ weighted anatomical image with the same axial slice placement and thickness as the EPI images was also acquired $(256 \times 256$ matrix size, 5 $\mathrm{mm}$ in thickness, $1 \mathrm{~mm}$ gap, TE/TR $=14 / 500 \mathrm{~ms}$ ).

\subsection{Image processing and analysis}

Functional image processing was conducted using customized Statistical Parametric Mapping (SPM) software (Frackowiack et al., 2004) and consisted of the following steps: reconstruction of EPI functional images using modified GE reconstruction software with off-resonance phase correction, slice-timing correction and Hanning-window apodization; extraction of physiological fluctuations such as cardiac and respiratory cycles from EPI image sequence (Frank et al., 2001); manual AC-PC re-orientation of all anatomical and EPI images; realignment of EPI images to correct for slight head movement between scans based on intracranial voxels (data sets with movement of greater than $1 / 3$ voxel over the study session were excluded); co-registration of functional EPI images to the corresponding highresolution anatomical image, based on rigid body transformation parameters of the reference T1 weighted anatomical image to the latter for each individual subject; stereotactic normalization to a standardized coordinate space (Montreal Neurological Institute 152 brain average T1-template [ICBM152_T1]) based on the high-resolution anatomical image; and spatial smoothing with an isotropic Gaussian kernel (FWHM $=7.5 \mathrm{~mm}$ ) to increase signalto-noise ratio.

A two-state voxel-wise correlational analysis (Kherif et al., 2002) was performed to evaluate the relationship between the relative cortisol level change and the average BOLD response per condition. First, a voxel-wise multiple linear regression model was employed at the individual subject level. This was comprised of the regressor of interest (stimulus onset times convolved with a prototypical hemodynamic response function) and covariates of no interest, the temporal first-order derivative of the principal regressors, global fluctuations, physiological fluctuations, realignment parameters, and scanning periods. The temporal global fluctuation estimated as the mean intensity within brain region of each volume was removed through proportional scaling, and an AR(1) model of the time course was used to accommodate temporal correlation in consecutive scans. Effects at every brain voxel were estimated using the EM (expectation maximization) algorithm, which resulted in a set of contrast images of condition-specific effects for each subject (including the effect of each

Psychoneuroendocrinology. Author manuscript; available in PMC 2014 December 01. 
condition vs. rest and the effects of between-condition comparisons), which were entered into the second stage group level fixed-effects correlational analysis to assess the withingroup effect sizes of the key hypotheses. Second, a voxel-wise correlational analysis using a multiple regression model in an ANCOVA setting at the group level was performed, with the condition-specific BOLD response as the dependent variable, the diurnal cortisol index as the independent variable, and specific demographic factors (age, gender, days from September 11th, 2001) incorporated as covariates of no interest.

A voxel-wise inference at the group level was then drawn according to Gaussian random field theory, focusing on the following a priori regions of interest (ROIs): bilateral amygdala, hippocampus/parahippocampus, vmPFC and hypothalamus. Except for the hypothalamus mask (which was generated in-house: see supplementary materials) ROI's were defined based on standard Automated Anatomical Labeling (AAL) masks created by the Neurofunctional Imaging Group (Tzourio-Mazoyer et al., 2002) with the vmPFC mask incorporating bilateral ventromedial, orbitofrontal, and anterior cingulate AAL regions. For these $a$ priori ROIs, correlations were considered significant if their initial voxel-wise $p$ values were less than 0.001 and family-wise error corrected $p$-values of the peaks within the ROIs were less than 0.05 . For regions outside the above ROIs, the correlations were considered significant if both the uncorrected voxel-wise $p$-values and the corrected $p$-values of the peaks were less than 0.001 .

\section{Results}

\subsection{Behavioral results}

3.1.1. Valence rating - WTC images were rated as significantly more negative than all other image types ( $p<0.0001$ ) except VIE. WTC mean, -2.27 (S.D. 0.81); NYC mean, . 8529 (S.D. 0.89); COU mean, 1.485 (S.D. 0.92) VIE, mean -1.88 (S.D. 0.77)

(Supplementary Fig. 1).

3.1.2. Reaction time-Subjects responded significantly more slowly to WTC images than to all other image types. WTC mean 992 s (S.D. 271); NYC mean 888.5 s (S.D. 210); COU mean 845 s (201); VIE mean, 934 s (S.D. 269). In particular, WTCvNYC was significant $p$ $<0.0095$, WTCvVIE $p<0.0344$, WTCvSUB $p<0.0046$, WTCvCOU $p<0.0008$ and WTCvSCR $p<0.0009$ (Supplementary Fig. 2).

3.1.3. Diurnal cortisol index-Each subject's diurnal cortisol index, reflecting his or her average diurnal cortisol excursion, ranged from .038 to $1.696 \mu \mathrm{g} / \mathrm{dL}$, mean 0.63 (S.D.: 0.22). The average value following waking (consisting of the awakening and awakening plus 30 $\min$ ) was $0.55 \mu \mathrm{g} / \mathrm{dL}$ (S.D.: 0.38). The average evening value (consisting of the last two samples taken at $1700 \mathrm{~h}$ and $2000 \mathrm{~h}$ ) was: 0.10 (S.D.: 0.05) (Fig. 2). Peak values in the morning and nadir in the evening are in accord with the well-established normal pattern (Smyth et al., 1997; Clow et al., 2004). A plot of the four collection times averaged across all participants demonstrates that the collection times captured the morning cortisol peak as well as the fall throughout the remainder of the day (Supplementary Fig. 3). 
3.1.4. Correlation of BOLD and cortisol-Significant findings within a priori ROIs are listed in Table 1. Significant findings outside these ROIs are listed in Table 2.

\subsection{Amygdala and hippocampus/parahippocampus}

There was a negative correlation between bilateral amygdalar activity and the diurnal cortisol index most notable in the WTCvSCR contrast. Specifically, the WTCvSCR contrast was statistically more negative than all other conditions versus SCR in the right amygdala statistically more negative than the COUvSCR contrast in all ROI's within the medial temporal lobe and statistically more negative than the VIEvSCR contrast in the left hippocampus/parahippocampus (Fig. 3).

This negative correlation was also present bilaterally in the amygdala and hippocampus/ parahippocampus in the WTC stand-alone (vs. rest) condition. It was present in the VIEvSCR contrast (bilaterally) and VIE stand-alone (on the left). Of all the stand-alone conditions (SUB, COU, VIE, WTC, NYC and SCR) only WTC and VIE - the two conditions designed to be emotionally negative - demonstrated a significant negative correlation between amygdalar activity and the diurnal cortisol index.

With regard to the hippocampus, the WTCvSCR and NYCvSCR contrasts demonstrated significant inverse correlations between bilateral ventral hippocampi and the diurnal cortisol index. Of note, these findings are driven in part by a significant positive correlation between diurnal cortisol index and the SCR stand-alone condition.

3.2.1. vmPFC - The stand-alone conditions, WTC and NYC, demonstrated negative correlations between activity in vmPFC (specifically the subgenual cingulate) and the diurnal cortisol index.

3.2.2. Hypothalamus-The stand-alone conditions, WTC, NYC, SCR, COU and SUB all demonstrated significant negative correlations between activation in hypothalamus and the diurnal cortisol index.

3.2.3. Non-correlational fMRI activations-Although the focus of this paper is on the relation between cortisol and brain activity, it is important to note that bilateral amygdala and hippocampus demonstrated increased BOLD activity in response to WTC imagery as compared to rest.

\section{Discussion}

\subsection{Behavioral results}

As expected, participants rated WTC images as significantly more negative than all other image type except VIE images. Participants also responded significantly more slowly to WTC images than to all other image types. Previous studies have demonstrated slowed reaction time when contrasting negative and neutral images, which may reflect a greater cognitive load due to both visualization of complex scenes and the associated cognitive demand and interference associated with increasing emotional content (Britton et al., 2006; 
Glascher et al., 2007). Taken together, these behavioral findings indicate that participants perceived the WTC images as emotionally negative.

\subsection{Correlational data}

4.2.1. Amygdala and hippocampus/parahippocampus-The primary result of this study consists of the negative correlation between bilateral both amygdalar and hippocampal/parahippocampal brain activity induced by WTC images and the diurnal cortisol index, a measure of HPA axis functioning. This indicates that subjects who typically demonstrate a greater amplitude of diurnal cortisol have less brain activation within the amygdala and hippocampus in response to emotionally negative, stress-related images. This negative correlation in bilateral medial temporal lobe limbic regions was consistently present when the WTC images were contrasted with the resting state, with scrambled images (a low-level visual control condition), and in contrast to a high-level control condition, COU, consisting of images judged most pleasant by subjects. When contrasted with other high-level control conditions (NYC, VIE and SUB), findings were significant unilaterally.

Examining the pattern of amygdalar and hippocampal/parahippocampal activity during each condition (vs. SCR) as shown in Fig. 3, it can be seen that the statistically most negative medial temporal lobe correlations with the diurnal cortisol index occurred as expected during the WTC condition, with the correlation weakening in association with progression from more aversive control conditions (VIE and NYC, which for reasons discussed below likely had contextual "bleed-over" effects from the WTC condition) to less aversive or pleasant control conditions (SCR, SUB, COU). The retention of significant findings in the right amygdala and left hippocampus/parahippocampus in the WTCvVIE contrast suggests that indeed the WTC images likely had greater emotional significance to study participants (none of whom were Vietnam veterans) because of their temporal and spatial proximity to the WTC attacks. In the case of the WTCvNYC contrast, that only the right amygdala demonstrated statistical significance suggests that images of New York City, especially when presented in close temporal proximity to WTC images, may have had negative emotional associations, reminding subjects (all of whom were New Yorkers) of the World Trade Center attacks, and potential future New York targets. This may relate to a more general process by which emotional meaning (WTC images) can generalize into neutral stimuli that are related to negative stimuli, as occurs in animals during aversive contextual conditioning (Siegmund and Wotjak, 2007) and in humans with anxiety disorders including PTSD (Felmingham et al., 2003).

Our findings of an inverse relationship between daily cortisol excursion and medial temporal lobe activity can be understood with reference to previous animal and human neuroimaging studies examining the relationship between cortisol and brain activation. In accordance with the findings of a reciprocal relationship between hippocampal activation and cortisol level de Leon et al. (1997) reported that administration of an exogenous bolus of hydrocortisone caused a bilateral reduction in hippocampal glucose uptake in healthy controls, as measured by [18F]-2-fluoro-deoxy-D-glucose positron emission tomography (FDG-PET). Electrical stimulation of the subiculum, CA1, CA2 and anterior regions of the hippocampus in humans has been shown to suppress plasma corticosteroid levels (Rubin et al., 1966). It can also be 
seen in the context of other work (Diamond et al., 1992) which documents that in mice, at high levels of glucocorticoids, there is a decrease in the number of primed burst potentiation in the CA1 region of the hippocampus. In particular, despite methodological differences, the present results are concordant with a prior study by Urry et al. (2006) in which subjects were asked to modulate felt emotion in response to negative images. An inverse relationship was found between the slope of diurnal cortisol and activation in limbic regions including the amygdala. These findings were interpreted as indicating that in healthy subjects, steeper daily cortisol slopes - considered to be the healthy and normative response - were associated with less amygdalar activity in response to negative stimuli. Similarly, we interpret the findings of the present study as reflecting the healthy response profile of the participants to emotional stimuli.

Studies of other populations, though not completely analogous, may support this model. In humans, administration of exogenous cortisol was preventative of the later development of PTSD symptoms in patients treated in an intensive care unit. (Schelling et al., 2004; Aerni et al., 2004; Soravia et al., 2006) Although it is not clear to what extent long-term cortisol administration mimics physiologically increased levels of diurnal salivary cortisol, this study adds an important perspective to behavioral changes that result from a prolonged increase in the level of glucocorticoids.

In another study Liberzon et al. (2007), identified a relationship between plasma cortisol level sampled before and after each of ten scans and brain activation elicited by emotional imagery. In particular, the rostral anterior cingulate, posterior cingulate and superior temporal gyrus demonstrated a relationship with pre-scan cortisol levels in healthy traumaexposed individuals. An earlier single photon emission computed tomography (SPECT) study demonstrated an inverse correlation between bilateral vmPFC activity (at rest) and morning cortisol levels in healthy trauma-exposed participants (Bonne et al., 2003).

The somewhat paradoxical finding that increased amygdala activity correlates with a decreased amplitude of salivary cortisol may relate to the highly coupled connection between the amygdala and hippocampus, both at the neuronal level and functionally in their regulation of the HPA axis, which may allow for the activity of one to influence firing in the other in the context of greater amplitudes of the diurnal cortisol secretion.

4.2.2. Hypothalamus and vmPFC—Correlation of diurnal cortisol index and activation of the hypothalamus and vmPFC (subgenual cingulate) was significant in the WTC and NYC stand-alone conditions, but was not present after correction for low-level visual processing (WTCvSCR and NYCvSCR contrasts). This indicates that the daily amplitude of cortisol may not be specifically related to response to emotional probes in healthy individuals as operationalized in this study, in these regions. It should be noted, however, that there was a trend towards a positive correlation between daily cortisol index and a different region of $\operatorname{vmPFC}(15,33,-18)(p<0.145)$ for the WTCvSCR contrast. Despite not reaching statistical significance, this trend is of interest in the context of previous neuroimaging studies revealing a reciprocal relationship between the medial PFC and mesotemporal limbic cortices (Rauch et al., 2006). In relation to the current findings, this reciprocal relationship between the ventral medial PFC and meso-temporal limbic cortices

Psychoneuroendocrinology. Author manuscript; available in PMC 2014 December 01. 
may represent a greater top-down modulation of meso-temporal reactivity to stress-related stimuli in individuals who have greater amplitudes of cortisol over the course of the day. This finding is anatomically and perhaps functionally distinct from the other mPFC site identified by the stand-alone WTC and NYC conditions.

\subsubsection{Potential mechanism relating the diurnal cortisol response and brain activation from the perspective of molecular and behavioral neuroscience-}

The central nervous system both regulates and is affected by activity of the HPA axis. In addition to mediating negative feedback effects on the HPA axis (de Leon et al., 1997), these receptors are present within the medial prefrontal cortex (mPFC), hippocampus, and amygdala - three limbic centers known to modulate the stress response (Reul and de Kloet, 1985; Fuxe et al., 1985; Ahima and Harlan, 1990; Herman, 1993; Herman et al., 2005). The differing affinities and localizations of the MR and GR suggests a mechanism by which the usual day cortisol level might have a different effect on regulation of the HPA axis and associated limbic centers than cortisol secreted in response to a stressor (Sapolsky et al., 1984; Herman et al., 1995; De Kloet et al., 1998; Herman and Mueller, 2006). In addition these receptors may become downregulated, be differentially expressed, or contain polymorphisms further altering the relationship between plasma cortisol levels and brain activity (Meyer et al., 2001). The interaction of genetic polymorphisms with an individual's experience of stressful life events can predispose an individual to psychiatric illness (Caspi et al., 2003; DeRijk and de Kloet, 2005).

As to the mechanisms of action of glucocorticoids on the brain, cortisol would be expected both to modulate gene transcription and to initiate signaling cascades at the plasma membrane as recently identified (Johnson et al., 2005). In relation to emotional processing, the diurnal rhythm of cortisol may be involved in the development and maintenance of a physiological set point, from which stress-induced limbic activity and cortisol changes modulate phasic neurobehavioral responses. In this model, the diurnal cortisol rhythm could act centrally to prime the neural circuits that terminate the HPA stress response, as has been shown previously in animal models (Akana et al., 1988; Jacobson et al., 1988).

\subsection{Limitations}

As discussed above, the relationship between cortisol and associated brain regions that contribute to HPA axis regulation is bi-directional. Underlying molecular and genetic processes may also contribute to the complex association between cortisol secretion and regional brain responses. The temporal and spatial resolution of fMRI, and the cortisol measurements employed (meant to address the usual diurnal range) preclude interpretations about direct interactions or causality. In regard to the methods, it is a limitation of this manuscript that two awakening cortisol samples were collected as opposed to three as indicated by (Hellhammer et al., 2007). This was not required of the study participants in order to increase subject compliance and decrease burden.

\subsection{Conclusions}

This study's findings contribute to an understanding of the neurophysiological stress response profile associated with the amplitude of the diurnal cortisol secretion. The primary

Psychoneuroendocrinology. Author manuscript; available in PMC 2014 December 01. 
focus of this manuscript is to determine the healthy relationship between diurnal cortisol rhythmicity and the BOLD response.

The present results suggest that a greater daily cortisol excursion is associated with less responsiveness of limbic regions associated with both the stress and fear response, perhaps mediated by enhanced ventral medial PFC modulation. The specific interrelation between cortisol and brain activity in these limbic centers can be examined in follow-up studies, and may be important in increasing our understanding of the role and consequences of diurnal cortisol variation in both healthy adaptation and psychiatric disorders. Knowledge of diurnal cortisol secretion and associated brain response profile may distinguish subjects who could be at increased risk of developing a future psychiatric disorder, PTSD in particular, through its relationship to fear/stress circuit activity.

\section{Supplementary Material}

Refer to Web version on PubMed Central for supplementary material.

\section{Acknowledgments}

Role of the funding source

Funding for this study was provided by NIMH Grant P50 MH58911-S1; the NIMH had no further role in study.

We would like to thank Wolfgang Engelien our computer engineer and Judith Allen our clinical coordinator for their valued contributions.

\section{References}

Aerni A, Traber R, Hock C, Roozendaal B, Schelling G, Papassotiropoulos A, Nitsch RM, Schnyder U, de Quervain DJ. Low-dose cortisol for symptoms of posttraumatic stress disorder. Am J Psychiatry. 2004; 161:1488-1490. [PubMed: 15285979]

Ahima RS, Harlan RE. Charting of type II glucocorticoid receptor-like immunoreactivity in the rat central nervous system. Neuroscience. 1990; 39:579-604. [PubMed: 1711170]

Akana SF, Jacobson L, Cascio CS, Shinsako J, Dallman MF. Constant corticosterone replacement normalizes basal adrenocorticotropin (ACTH) but permits sustained ACTH hyper-secretion after stress in adrenalectomized rats. Endocrinology. 1988; 122:1337-1342. [PubMed: 2831027]

Bierer LM, Tischler L, Labinsky E, Cahill S, Foa E, Yehuda R. Clinical correlates of 24-h cortisol and norepinephrine excretion among subjects seeking treatment following the world trade center attacks on 9/11. Ann N Y Acad Sci. 2006; 1071:514-520. [PubMed: 16891610]

Bonne O, Gilboa A, Louzoun Y, Brandes D, Yona I, Lester H, Barkai G, Freedman N, Chisin R, Shalev AY. Resting regional cerebral perfusion in recent posttraumatic stress disorder. Biol Psychiatry. 2003; 54:1077-1086. [PubMed: 14625150]

Bremner JD. Traumatic stress: effects on the brain. Dialogues Clin Neurosci. 2006; 8:445-461. [PubMed: 17290802]

Britton JC, Taylor SF, Sudheimer KD, Liberzon I. Facial expressions and complex IAPS pictures: common and differential networks. NeuroImage. 2006; 31:906-919. [PubMed: 16488159]

Caspi A, Sugden K, Moffitt TE, Taylor A, Craig IW, Harrington H, McClay J, Mill J, Martin J, Braithwaite A, Poulton R. Influence of life stress on depression: moderation by a polymorphism in the 5-HTT gene. Science (New York, NY). 2003; 301:386-389.

Charney DS. Psychobiological mechanisms of resilience and vulnerability: implications for successful adaptation to extreme stress. Am J Psychiatry. 2004; 161:195-216. [PubMed: 14754765] 
Clow A, Thorn L, Evans P, Hucklebridge F. The awakening cortisol response: methodological issues and significance. Stress. 2004; 7:29-37. [PubMed: 15204030]

Dannlowski U, Ohrmann P, Bauer J, Kugel H, Arolt V, Heindel W, Suslow T. Amygdala reactivity predicts automatic negative evaluations for facial emotions. Psychiatry Res. 2007; 154:13-20. [PubMed: 17182226]

De Kloet ER, Vreugdenhil E, Oitzl MS, Joels M. Brain corticosteroid receptor balance in health and disease. Endocr Rev. 1998; 19:269-301. [PubMed: 9626555]

de Leon MJ, McRae T, Rusinek H, Convit A, De Santi S, Tarshish C, Golomb J, Volkow N, Daisley $\mathrm{K}$, Orentreich N, McEwen B. Cortisol reduces hippocampal glucose metabolism in normal elderly, but not in Alzheimer's disease. J Clin Endocrinol Metab. 1997; 82:3251-3259. [PubMed: 9329348]

DeRijk R, de Kloet ER. Corticosteroid receptor genetic polymorphisms and stress responsivity. Endocrine. 2005; 28:263-270. [PubMed: 16388115]

Diamond DM, Bennett MC, Fleshner M, Rose GM. Inverted-U relationship between the level of peripheral corticosterone and the magnitude of hippocampal primed burst potentiation. Hippocampus. 1992; 2:421-430. [PubMed: 1308198]

Felmingham KL, Bryant RA, Gordon E. Processing angry and neutral faces in post-traumatic stress disorder: an event-related potentials study. Neuroreport. 2003; 14:777-780. [PubMed: 12692482]

Frackowiack, RSJ.; Friston, KJ.; Frith, C.; Dolan, R.; Price, CJ.; Zeki, S. Human Brain Function. Ashburner, J.; Penny, W., editors. Elsevier/Academic Press; 2004.

Frank LR, Buxton RB, Wong EC. Estimation of respiration-induced noise fluctuations from undersampled multislice fMRI data. Magn Reson Med. 2001; 45:635-644. [PubMed: 11283992]

Fuxe K, Wikstrom AC, Okret S, Agnati LF, Harfstrand A, Yu ZY, Granholm L, Zoli M, Vale W, Gustafsson JA. Mapping of glucocorticoid receptor immunoreactive neurons in the rat tel- and diencephalon using a monoclonal antibody against rat liver glucocorticoid receptor. Endocrinology. 1985; 117:1803-1812. [PubMed: 4042964]

Glascher J, Rose M, Buchel C. Independent effects of emotion and working memory load on visual activation in the lateral occipital complex. J Neurosci. 2007; 27:4366-4373. [PubMed: 17442821]

Gu H, Feng H, Zhan W, Xu S, Silbersweig DA, Stern E, Yang Y. Single-shot interleaved z-shim EPI with optimized compensation for signal losses due to susceptibility-induced field inhomogeneity at 3 T. NeuroImage. 2002; 17:1358-1364. [PubMed: 12414275]

Gur RC, Schroeder L, Turner T, McGrath C, Chan RM, Turetsky BI, Alsop D, Maldjian J, Gur RE. Brain activation during facial emotion processing. NeuroImage. 2002; 16:651-662. [PubMed: 12169250]

Hellhammer J, Fries E, Schweisthal OW, Schlotz W, Stone AA, Hagemann D. Several daily measurements are necessary to reliably assess the cortisol rise after awakening: state- and trait components. Psychoneuroendocrinology. 2007; 32:80-86. [PubMed: 17127010]

Herman JP. Regulation of adrenocorticosteroid receptor mRNA expression in the central nervous system. Cell Mol Neurobiol. 1993; 13:349-372. [PubMed: 8252607]

Herman JP, Adams D, Prewitt C. Regulatory changes in neuroendocrine stress-integrative circuitry produced by a variable stress paradigm. Neuroendocrinology. 1995; 61:180-190. [PubMed: 7753337]

Herman JP, Mueller NK. Role of the ventral subiculum in stress integration. Behav Brain Res. 2006; 174:215-224. [PubMed: 16876265]

Herman JP, Ostrander MM, Mueller NK, Figueiredo H. Limbic system mechanisms of stress regulation: hypothalamopituitary-adrenocortical axis. Prog Neuropsychopharmacol Biol Psychiatry. 2005; 29:1201-1213. [PubMed: 16271821]

Herman JP, Seroogy K. Hypothalamic-pituitary-adrenal axis, glucocorticoids, and neurologic disease. Neurol Clin. 2006; 24:461-481. vi. [PubMed: 16877118]

Holsboer F. The corticosteroid receptor hypothesis of depression. Neuropsychopharmacology. 2000; 23:477-501. [PubMed: 11027914]

Jacobson L, Akana SF, Cascio CS, Shinsako J, Dallman MF. Circadian variations in plasma corticosterone permit normal termination of adrenocorticotropin responses to stress. Endocrinology. 1988; 122:1343-1348. [PubMed: 2831028] 
Johnson LR, Farb C, Morrison JH, McEwen BS, LeDoux JE. Localization of glucocorticoid receptors at postsynaptic membranes in the lateral amygdala. Neuroscience. 2005; 136:289-299. [PubMed: 16181741]

Kathol RG, Jaeckle RS, Lopez JF, Meller WH. Pathophysiology of HPA axis abnormalities in patients with major depression: an update. Am J Psychiatry. 1989; 146:311-317. [PubMed: 2645793]

Kemeny ME, Dickerson SS. Acute stressors and cortisol responses: a theoretical integration and synthesis of laboratory research. Psychol Bull. 2004; 130:355-391. [PubMed: 15122924]

Kherif F, Poline JB, Flandin G, Benali H, Simon O, Dehaene S, Worsley KJ. Neuroimage. 2002; 16(4):1068-1083. [PubMed: 12202094]

Lane RD, Reiman EM, Bradley MM, Lang PJ, Ahern GL, Davidson RJ, Schwartz GE. Neuroanatomical correlates of pleasant and unpleasant emotion. Neuropsychologia. 1997; 35:1437-1444. [PubMed: 9352521]

Liberzon I, Britton JC, King AP, Phan KL, Abelson JL, Taylor SF. Paralimbic and medial prefrontal cortical involvement in neuroendocrine responses to traumatic stimuli. Am J Psychiatry. 2007; 8:1250-1258. [PubMed: 17671289]

Lupien SJ, Wilkinson CW, Briere S, Menard C, Ng Ying Kin NM, Nair NP. The modulatory effects of corticosteroids on cognition: studies in young human populations. Psychoneuroendocrinology. 2002; 27:401-416. [PubMed: 11818174]

Mackenzie EM, Odontiadis J, Le Melledo JM, Prior TI, Baker GB. The relevance of neuroactive steroids in schizophrenia, depression, and anxiety disorders. Cell Mol Neurobiol. 2007

McEwen BS. The neurobiology and neuroendocrinology of stress. Implications for post-traumatic stress disorder from a basic science perspective. Psychiatr Clin North Am. 2002; 25:469-494. ix. [PubMed: 12136511]

McEwen BS. Glucocorticoids, depression, and mood disorders: structural remodeling in the brain. Metabolism. 2005; 54:20-23. [PubMed: 15877308]

Miller MM, McEwen BS. Establishing an agenda for translational research on PTSD. Ann N Y Acad Sci. 2006; 1071:294-312. [PubMed: 16891579]

Meyer U, van Kampen M, Isovich E, Flugge G, Fuchs E. Chronic psychosocial stress regulates the expression of both GR and MR mRNA in the hippocampal formation of tree shrews. Hippocampus. 2001; 11:329-336. [PubMed: 11769314]

Neylan TC, Brunet A, Pole N, Best SR, Metzler TJ, Yehuda R, Marmar CR. PTSD symptoms predict waking salivary cortisol levels in police officers. Psychoneuroendocrinology. 2005; 30:373-381. [PubMed: 15694117]

Oei NY, Everaerd WT, Elzinga BM, van Well S, Bermond B. Psychosocial stress impairs working memory at high loads: an association with cortisol levels and memory retrieval. Stress. 2006; 9:133-141. [PubMed: 17035163]

Olff M, Guzelcan Y, de Vries GJ, Assies J, Gersons BP. HPA- and HPT-axis alterations in chronic posttraumatic stress disorder. Psychoneuroendocrinology. 2006; 31:1220-1230. [PubMed: 17081699]

Phan KL, Taylor SF, Welsh RC, Ho SH, Britton JC, Liberzon I. Neural correlates of individual ratings of emotional salience: a trial-related fMRI study. NeuroImage. 2004; 21:768-780. [PubMed: 14980580]

Radley JJ, Morrison JH. Repeated stress and structural plasticity in the brain. Ageing Res Rev. 2005; 4:271-287. [PubMed: 15993654]

Rauch SL, Shin LM, Phelps EA. Neurocircuitry models of posttraumatic stress disorder and extinction: human neuroimaging research—past, present, and future. Biol Psychiatry. 2006; 60:376-382. [PubMed: 16919525]

Reul JM, de Kloet ER. Two receptor systems for corticosterone in rat brain: microdistribution and differential occupation. Endocrinology. 1985; 117:2505-2511. [PubMed: 2998738]

Risbrough VB, Stein MB. Role of corticotropin releasing factor in anxiety disorders: a translational research perspective. Horm Behav. 2006; 50:550-561. [PubMed: 16870185]

Rubin RT, Mandell AJ, Crandall PH. Corticosteroid responses to limbic stimulation in man: localization of stimulus sites. Science (New York, N Y). 1966; 153:767-768. 
Sapolsky RM, Krey LC, McEwen BS. Glucocorticoid-sensitive hippocampal neurons are involved in terminating the adrenocortical stress response. Proc Natl Acad Sci USA. 1984; 81:6174-6177. [PubMed: 6592609]

Schelling G, Roozendaal B, De Quervain DJ. Can post-traumatic stress disorder be prevented with glucocorticoids? Ann N Y Acad Sci. 2004; 1032:158-166. [PubMed: 15677403]

Siegmund A, Wotjak CT. Hyperarousal does not depend on trauma-related contextual memory in an animal model of Post-traumatic Stress Disorder. Physiol Behav. 2007; 90:103-107. [PubMed: 17049568]

Smyth JM, Ockenfels MC, Gorin AA, Catley D, Porter LS, Kirschbaum C, Hellhammer DH, Stone AA. Individual differences in the diurnal cycle of cortisol. Psychoneuroendocrinology. 1997; 22:89-105. [PubMed: 9149331]

Soravia LM, Heinrichs M, Aerni A, Maroni C, Schelling G, Ehlert U, Roozendaal B, de Quervain DJ. Glucocorticoids reduce phobic fear in humans. Proc Natl Acad Sci USA. 2006; 103:5585-5590. [PubMed: 16567641]

Sotres-Bayon F, Bush DE, LeDoux JE. Emotional perseveration: an update on prefrontal-amygdala interactions in fear extinction. Learn Mem. 2004; 11:525-535. [PubMed: 15466303]

Taylor SF, Phan KL, Decker LR, Liberzon I. Subjective rating of emotionally salient stimuli modulates neural activity. NeuroImage. 2003; 18:650-659. [PubMed: 12667842]

Tzourio-Mazoyer N, Landeau B, Papathanassiou D, Crivello F, Etard O, Delcroix N, Mazoyer B, Joliot M. Automated anatomical labeling of activations in SPM using a macroscopic anatomical parcellation of the MNI MRI single-subject brain. NeuroImage. 2002; 15:273-289. [PubMed: 11771995]

Urry HL, van Reekum CM, Johnstone T, Kalin NH, Thurow ME, Schaefer HS, Jackson CA, Frye CJ, Greischar LL, Alexander AL, Davidson RJ. Amygdala and ventromedial prefrontal cortex are inversely coupled during regulation of negative affect and predict the diurnal pattern of cortisol secretion among older adults. J Neurosci. 2006; 26:4415-4425. [PubMed: 16624961]

Wang J, Rao H, Wetmore GS, Furlan PM, Korczykowski M, Dinges DF, Detre JA. Perfusion functional MRI reveals cerebral blood flow pattern under psychological stress. Proc Natl Acad Sci USA. 2005; 102:17804-17809. [PubMed: 16306271]

Yehuda R. Current status of cortisol findings in post-traumatic stress disorder. Psychiatr Clin North Am. 2002; 25:341-368. vii. [PubMed: 12136504]

Yehuda R, Giller EL, Southwick SM, Lowy MT, Mason JW. Hypothalamic-pituitary-adrenal dysfunction in posttraumatic stress disorder. Biol Psychiatry. 1991; 30:1031-1048. [PubMed: 1661614]

Young EA, Breslau N. Saliva cortisol in posttraumatic stress disorder: a community epidemiologic study. Biol Psychiatry. 2004; 56:205-209. [PubMed: 15271590]

\section{Appendix A. Supplementary data}

Supplementary data associated with this article can be found, in the online version, at doi: 10.1016/j.psyneuen.2008.11.011. 


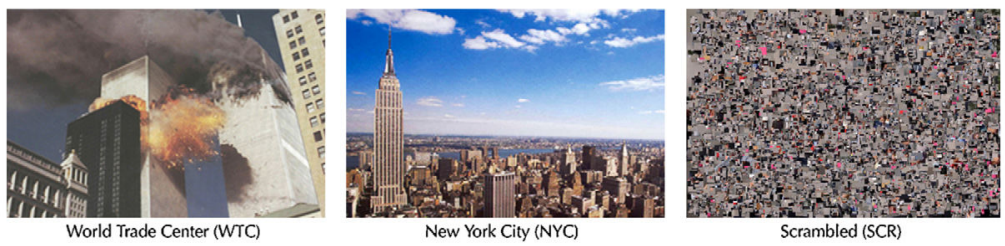

Figure 1.

Example of stimuli used in the present study. 


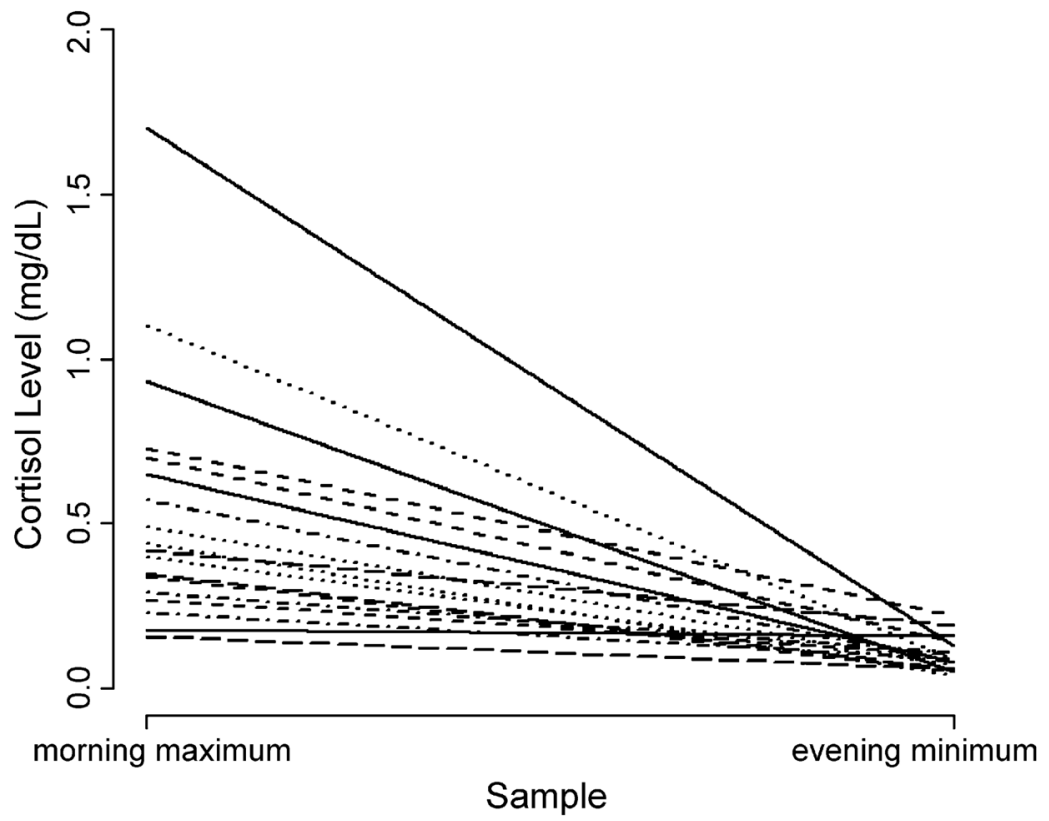

Figure 2.

This image depicts the range of each subject's diurnal cortisol rhythm. The morning maximum value, is the average of the maximum cortisol value (either the wake up or wake up plus 30 min samples) for each of the 3 days. The evening minimum is the average of either 5 p.m. or 8 p.m. sample (whichever had the lowest cortisol level) from each of the 3 days. This plot demonstrates the expected decline in the level of salivary cortisol across the day. 


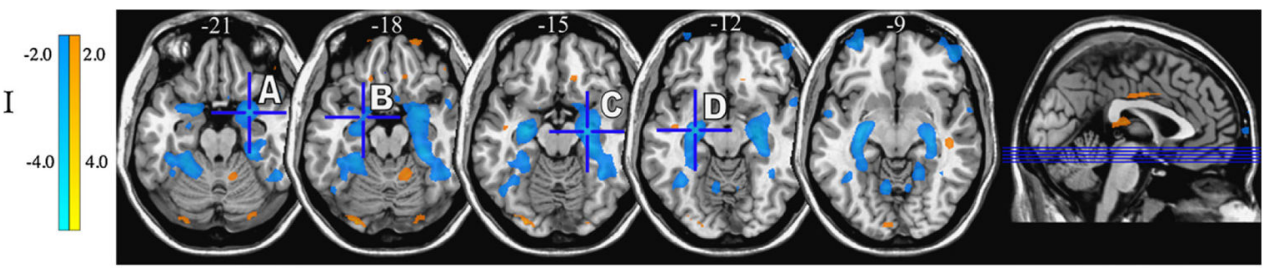

(A) Right Amygdala

(B) Left Amygdala

(C) Right Hippocampus

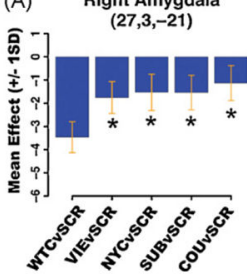

(D) Left Hippocampus

II
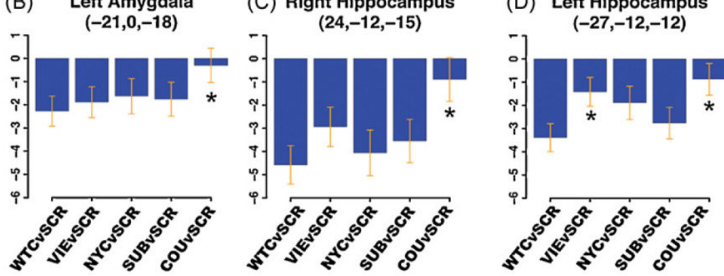

Figure 3.

Medial temporal lobe BOLD activity correlations with derived cortisol index for each experimental condition. (I) Statistical parametric map ( $p_{\text {uncorrected }}<0.001$; overlaid onto T1 canonical axial sections $z=-21$ to $z=-9$ ) showing positive (yellow) and negative (blue) correlations in BOLD activity between the WTC (vs. SCR) contrast and the derived diurnal cortisol index. Note the significant negative correlations in bilateral amygdala and hippocampus. (II) Effect size plots show the correlation with the diurnal cortisol index for each medial temporal lobe ROI maximum $\$$ given for each experimental condition (vs. SCR). *Conditions, which differ significantly $\left(p_{\text {corrected }}<0.05\right)$ from the WTC condition in that ROI. Note that in the right amygdala, the negative correlation with derived cortisol index is significantly stronger for WTC than for all other conditions; this general pattern holds true in other medial temporal lobe ROI’s seen above. *Peak voxel within [R or L] amygdala proper was plotted, rather than another local maxima [coordinates] technically within the ROI, but located in the amygdale/hippocampal border zone. 


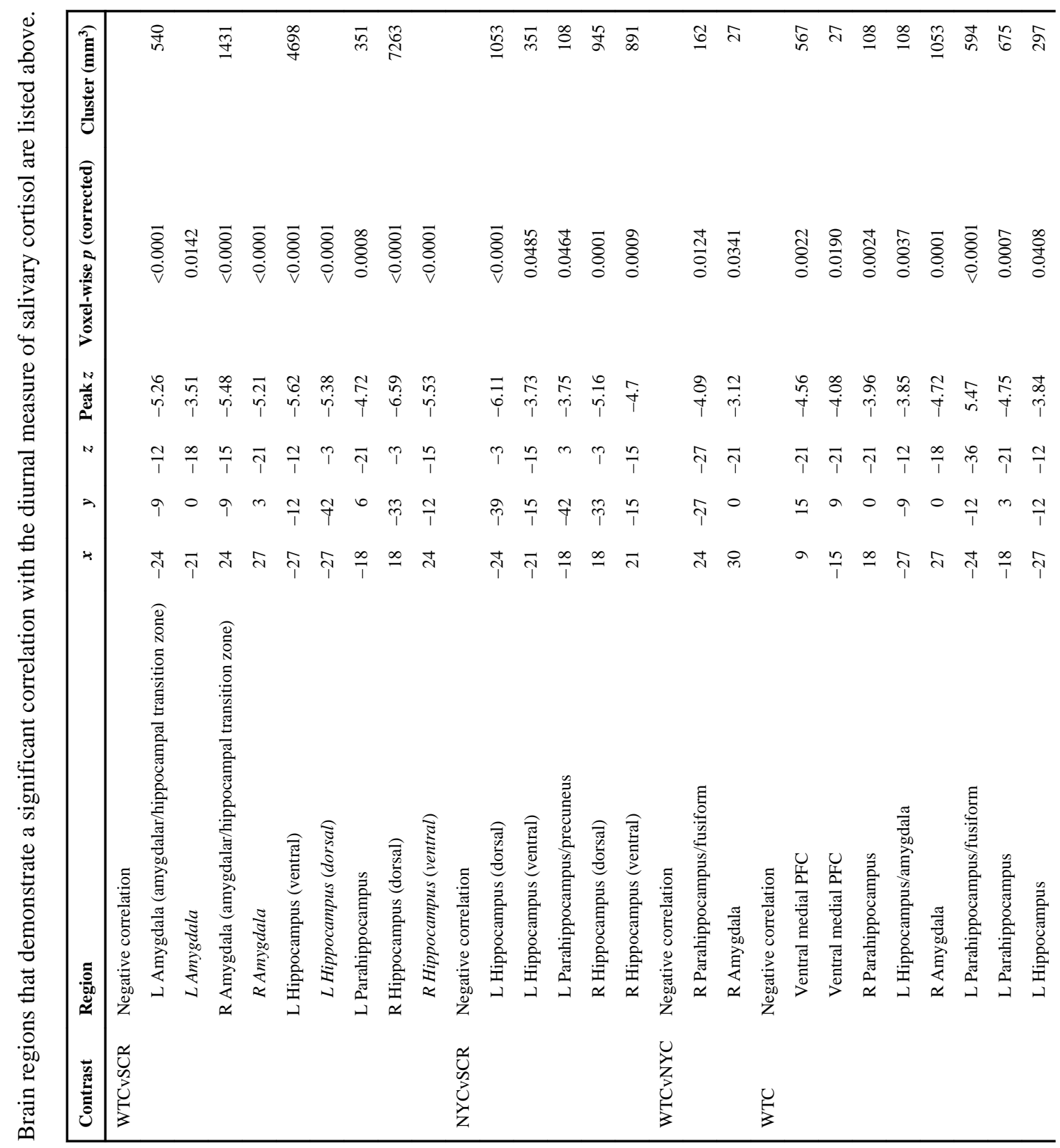

Psychoneuroendocrinology. Author manuscript; available in PMC 2014 December 01. 


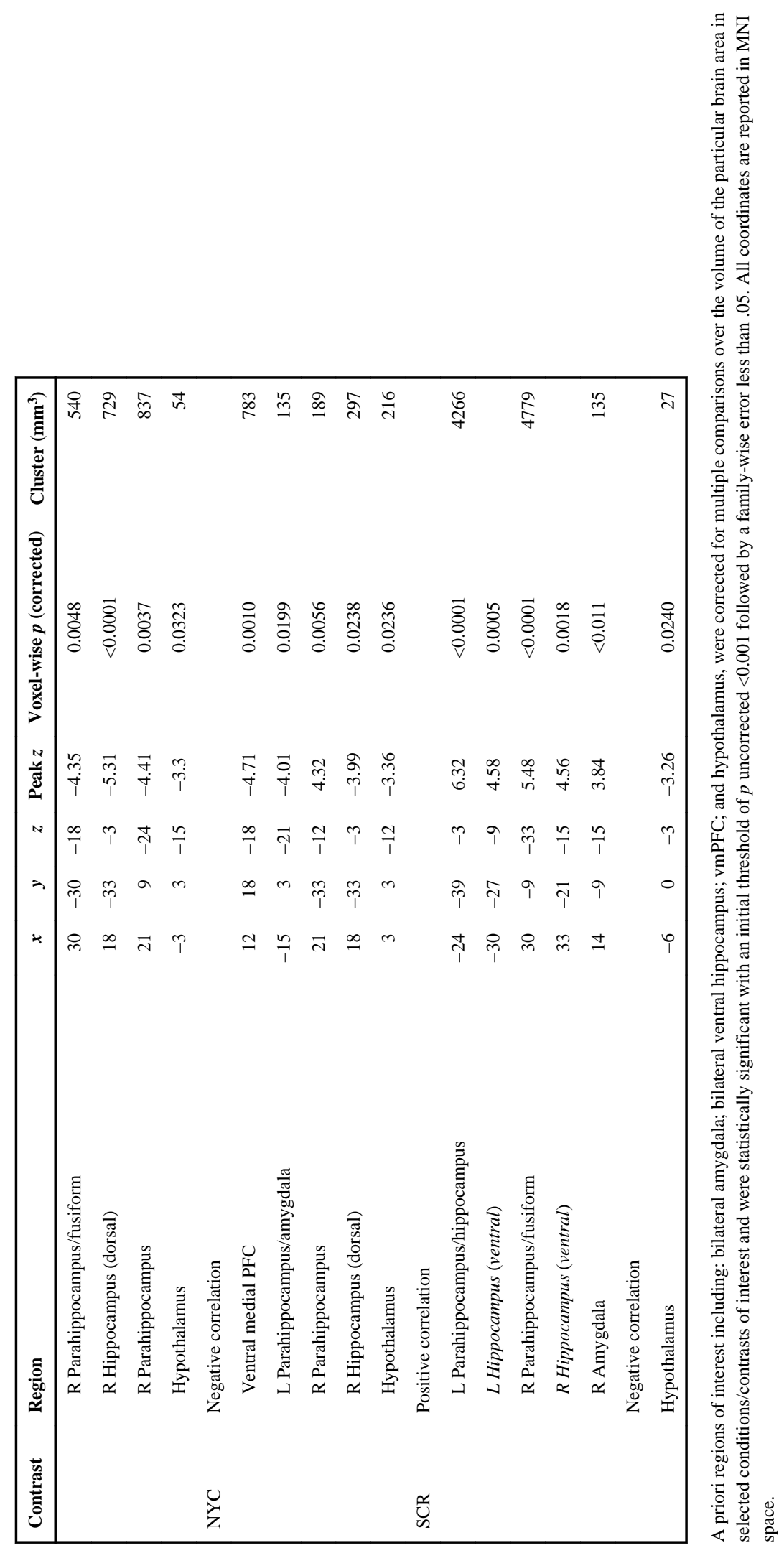

Psychoneuroendocrinology. Author manuscript; available in PMC 2014 December 01. 


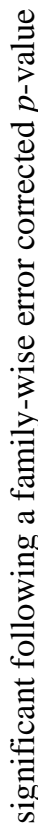

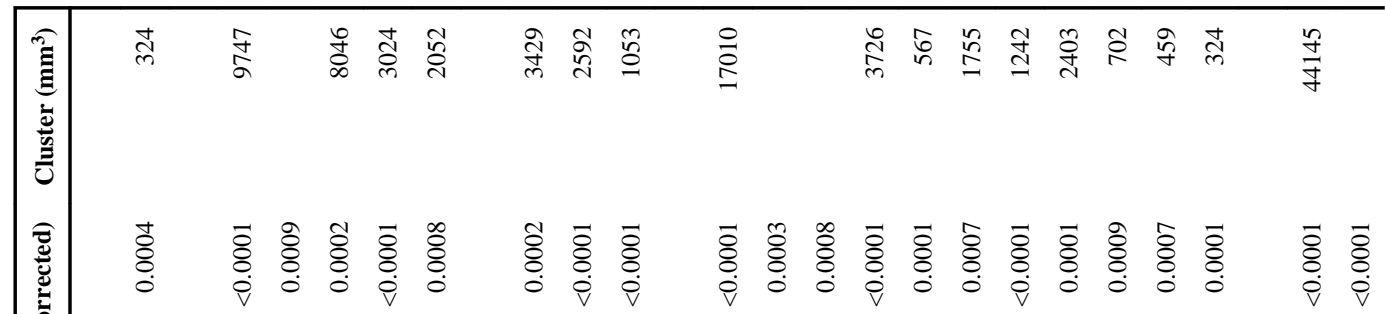

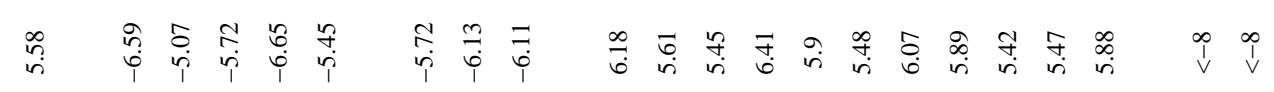

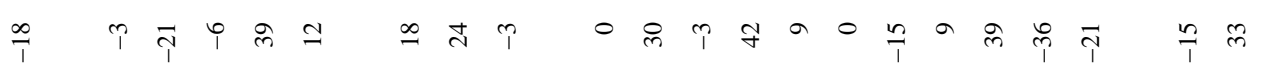

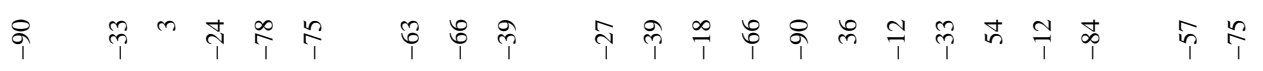

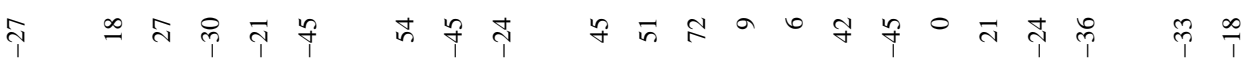

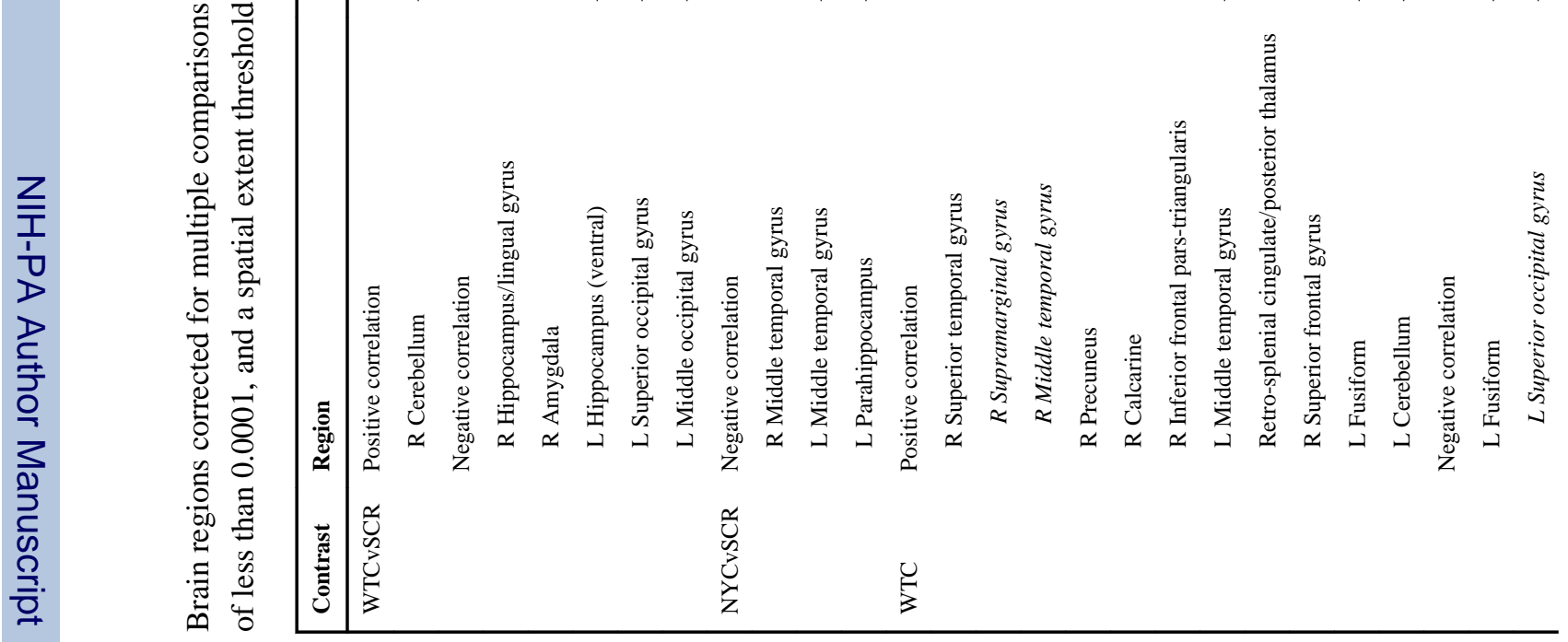
Psychoneuroendocrinology. Author manuscript; available in PMC 2014 December 01. 


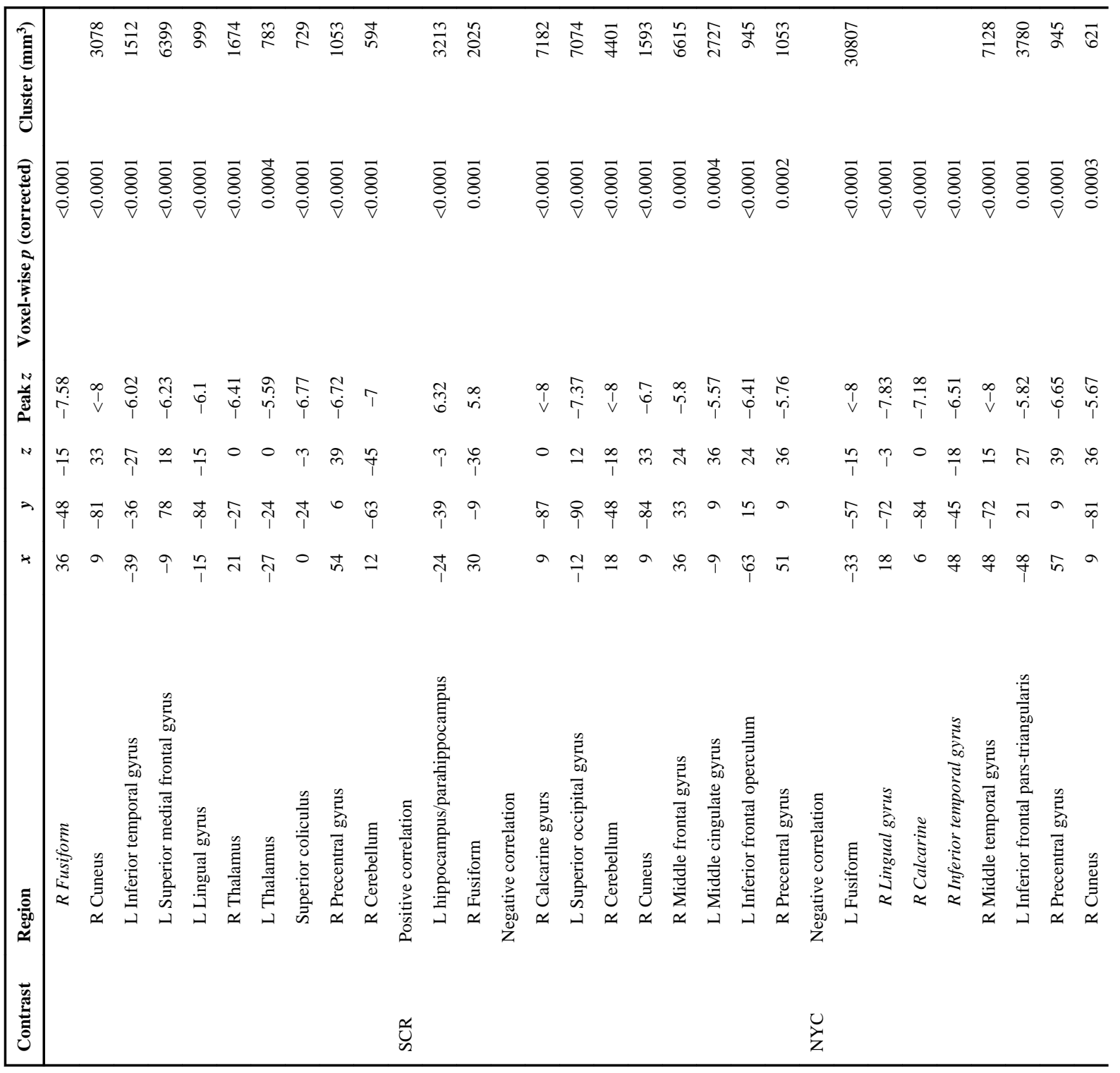




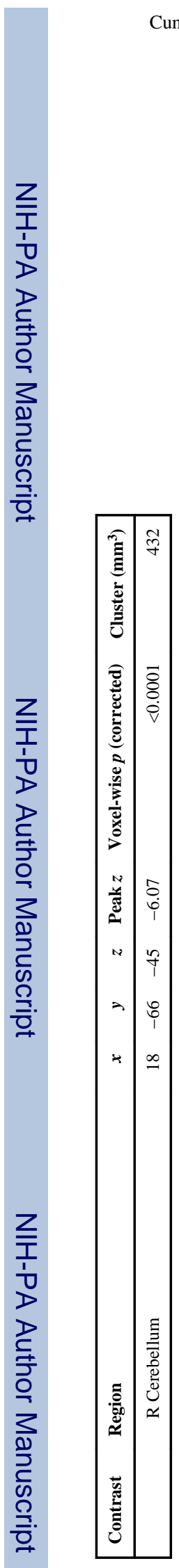

